\title{
EFECTO DE LA TEMPERATURA EN EL CRECIMIENTO MICROBIANO Y LA BIOLIXIVIACIÓN SOBRE LA CALCOPIRITA POR UN CULTIVO MICROBIANO BIOLIXIVIANTE
}

\author{
EFFECT OF TEMPERATURE ON MICROBIAL GROW'TH AND \\ BIOLEACHING CHALCOPYRITE ON CULTURE BY MICROBIAL \\ BIOLIXIVIANTE
}

\author{
${ }^{1}$ Sandra Verónica Delgado Cruz; ${ }^{2}$ Daladier Castillo Cotrina
}

\begin{abstract}
RESUMEN
Se determinó el efecto de la temperatura y el grado de correlación en el crecimiento microbiano y la biolixiviación sobre la calcopirita por un cultivo microbiano biolixiviante, para lo cual se trabajó con muestra de los botaderos de las pilas de lixiviación de la empresa minera Southern Perú Cooper Corporation. Se tuvo 4 tratamientos experimentales de $25,40,55$ y $70^{\circ} \mathrm{C}$, con una doble repetición. El tratamiento que obtuvo una mayor biooxidación de fierro II, biolixiviación de cobre y mayor concentración microbiana, fue el tratamiento experimental de $70^{\circ} \mathrm{C}$; la concentración microbiana fue de 8,20411998 unidades logarítmicas de cel/ml a las 312 horas, la biolixiviación de cobre máxima fue de $0,275038931 \mathrm{~g} / \mathrm{l}$. El grado de correlación entre la curva de crecimiento microbiano y la biooxidación del fierro tuvo un valor de 0,922207698; la correlación entre la biooxidación del fierro y la biolixiviación de cobre fue de 0,882478032.
\end{abstract}

Palabras clave: Biolixiviación, biooxidación, calcopirita, microorganismos biolixiviantes.

ABSTRACT

The effect of temperature and degree of correlation in microbial growth and bioleaching of chalcopyrite for biolixiviante microbial culture was determined, for which worked with sample dumps heap leach mining company Southern Peru Copper Corporation. Four experimental treatment of $25,40,55$ y $70^{\circ} \mathrm{C}$ were performed with a double repetition. The treatment had a higher biooxidation iron II, copper bioleaching microbial higher concentration, the experimental treatment was $70^{\circ} \mathrm{C}$; microbial concentration was $8,20411998 \mathrm{log}$ units of cells / $\mathrm{ml}$ at 312 hours, the maximum copper bioleaching was 0,275038931 g / I. The degree of correlation between microbial growth curve and the bio-oxidation of iron had a value of 0,922207698; the correlation between the bio-oxidation of iron and copper bioleaching was 0,882478032 .

Keywords: Bioleaching, biooxidation, chalcopyrite, biolixiviantes microorganisms.

\section{INTRODUCCIÓN}

La lixiviación es una técnica ampliamente utilizada en metalurgia extractiva que convierte los metales en sales solubles, pero que trae consigo significativos impactos ambientales, que perduran en el tiempo. La existencia de importantes recursos de baja ley que son remanentes de la explotación de minerales más ricos, sumado a los primeros indicios de agotamiento de las reservas minerales oxidadas, impulsó a los investigadores a buscar técnicas rentables y eficientes de recuperación del cobre. Esto los llevó a encontrar que ciertas bacterias catalizaban la lixiviación de los minerales sulfurados, haciendo rentable su procesamiento (CIMM, 2005).

La utilización de estas bacterias se justifica cuando el mineral sulfurado de un yacimiento cuprífero es de baja ley o tiene menos de un $0,5 \%$ de cobre, situación en la que el proceso productivo tradicional de pirometalurgia deja de ser rentable, y se buscan nuevos procesos, más baratos y eficientes.

En la actualidad la biolixiviación se ha convertido en una tecnología alternativa, más económica y ambientalmente aceptable (Ly, 2003).La biolixiviación es un proceso en el cual se emplean microorganismos para disolver los minerales, en este caso de calcopirita, no genera contaminación

'Biólogo - Microbiólogo. Laboratorio de Microbiología Industrial y Biotecnología, Facultad de Ciencias de la Universidad Nacional Jorge Basadre Grohmann. Tacna-Perú

"Magister en Ciencias con mención en Microbiología Industrial y Biotecnología, Biólogo - Microbiólogo, Jefe del Laboratorio de Microbiología Industrial y Biotecnología. Docente de la Facultad de Ciencias de la Universidad Nacional Jorge Basadre Grohmann. Tacna - Perú. 
Delgado, S. \& Castillo D. Efecto de la temperatura en el crecimiento microbiano y la biolixiviación sobre la calcopirita por un cultivo microbiano biolixiviante.

ambiental y su empleo es mucho más rentable que la lixiviación normal. En nuestro país, la biolixiviación es una nueva tecnología que está siendo poco a poco implementada en los diversos yacimientos mineros. En Tacna, en el yacimiento minero de Southern Perú Cooper Corporation, la biolixiviación está dando sus primeros pasos, estando aún en la etapa de experimentación en laboratorio.

La calcopirita es el mineral más refractario y abundante de los sulfuros de cobre por lo que la metalurgia extractiva de este metal se basa principalmente en este mineral (Jeffrey y F. Lawson, 2000). Es la fuente de cobre más abundante en el mundo y es, además, uno de los minerales más recalcitrantes en los procesos de hidrometalurgia (Constanza, 2000). Por esta razón el cobre es extraído principalmente por pirometalúrgia.

Diversas investigaciones han demostrado que para la realización de una mejor biolixiviación, es importante el uso de consorcios microbianos biolixiviantes, ya que cada microorganismo presente en el consorcio, genera un ambiente favorable y adecuado para el desarrollo del otro, logrando una mayor interacción, un espacio adecuado para su desarrollo y su actividad lixiviante (Acevedo, 2005). Entre todos los microorganismos lixiviantes presentes en los consorcios, los más empleados en biolixiviación son Acidithiobacillus ferroxidans y Aciditbiobacillus thiooxidans, también se encuentran Leptobacillus ferroxidans, estos microorganismos presentan, entre sus características principales que pueden vivir en ambientes hasta de un $\mathrm{pH}$ de 1 y son quimiolitoautótrofos, ya que tienen como fuente de energía, componentes inorgánicos (Orrantia, 1997).

La biolixiviación microbiana ocurre con diferentes factores acondicionados como son el pH bajo (1-2), los nutrientes, la presencia de metales pesados, la temperatura, la luz, oxígeno y dióxido de carbono (Rivera, 2011). Claro está que antes de que ocurra un proceso de biolixiviación tiene que ocurrir la biooxidación del Fierro. La biooxidación en un proceso que ocurre antes de la biolixiviación es un pretratamiento para la extracción del cobre, en este proceso ciertos microorganismos oxidan los sulfuros a través de mecanismos de acción directa e indirecta (Segura, 1998). Estos microorganismos utilizan como fuente primaria de energía las especies reducidas de fierro y azufre, y el CO. como fuente de carbono para su síntesis celular (Rivadeneira, 2006). Por lo tanto existe una correspondencia directa entre la biooxidación del Fierro y la biolixiviación del cobre.

En este trabajo el objetivo fue conocer la temperatura ideal y su efecto sobre el crecimiento microbiano y la capacidad biolixiviante del cultivo nativo microbiano en presencia de calcopirita.

\section{MATERIALESY MÉTODOS}

\section{Ubicación y delimitación del área de muestreo}

El mineral lixiviado fue muestreado de los botaderos de lixiviación de la empresa Southern Perú Cooper Corporation, ubicada en Toquepala en el departamento de Tacna. Se seleccionaron 5 botaderos con mayor actividad microbiana. Se determinó por botadero un área estándar de $1 \mathrm{~m}^{2}$ considerando puntos con actividad microbiana (Figura 1) (Arias \& Piñeros, 2008).

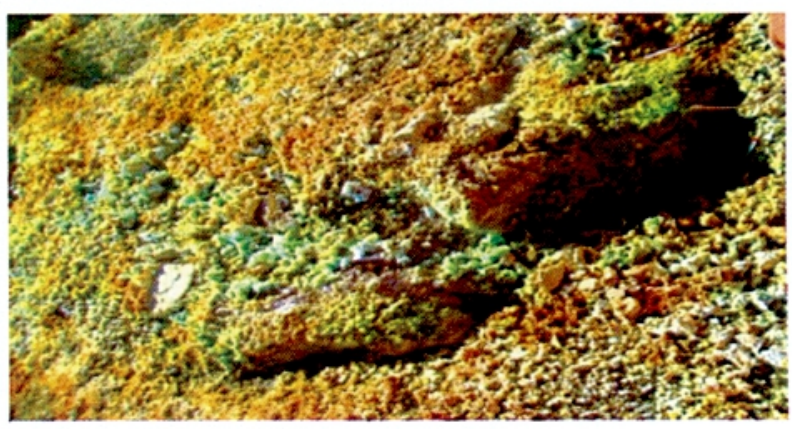

Figura 1. Área de toma de muestra

\section{Colección de la muestra}

Se colectaron un total de 5 muestras (una por botadero), cada muestra contuvo $3 \mathrm{~kg}$ de mineral lixiviado recogido del área de $1 \mathrm{~m}^{2}$ con ayuda de una pala. Estas fueron transportadas en baldes al laboratorio de Micología de la Facultad de Ciencias de la Universidad Nacional Jorge Basadre Grohmann para su procesamiento.

\section{Enriquecimiento del mineral lixiviado}

Se tomó 1,5 kg del mineral lixiviado y se sumergió en 4 litros de medio líquido $9 \mathrm{~K}$ Silverman y Lundgren modificado, a pH 1,8 ajustado con $\mathrm{H}_{2} \mathrm{SO}_{4}$, en baldes de $5 \mathrm{~L}$ de capacidad, los cuales fueron incubados a temperatura ambiente, con una aireación de 1 vvm durante 15 días (Saavedra, 2009).

\section{Aislamiento del cultivo microbiano biolixiviante en medio sólido}

En placas Petri con medio 9K sólido se incorporó $0,1 \mathrm{ml}$ del cultivo de enriquecimiento de mineral y se sembró con ayuda de un asa de Drigalsky por extensión. Las placas se incubaron a temperatura ambiente $\left(25^{\circ} \mathrm{C}\right)$ durante 15 a 20 días, tiempo en que aparecieron las colonias bacterianas compatibles a Acidithiobacillus ferroxidans por haber sido gram negativo y presentar precipitados de color rojo naranja.

\section{Obtención del inóculo microbiano biolixiviante}

Del cultivo de enriquecimiento, se tomó $5 \mathrm{ml}$ y se inoculó a $100 \mathrm{ml}$ del medio de cultivo $9 \mathrm{k}$ contenido en un biorreactor de $1000 \mathrm{~cm}^{3}$ de capacidad con una aireación de 1 vvm y se incubó a temperatura ambiente hasta que el cultivo estuvo en fase logarítmica, determinada por recuentos en cámara de Neubauer para observar que la dinámica de crecimiento fuera constante. Se realizó un recuento final de células en cámara de Neubauer para establecer la concentración inicial de células del inóculo.

\section{Caracterización y preparación del mineral calcopirita a lixiviar en la experimentación}

Se aplicó la técnica del cuarteo a todo el mineral para tomar una muestra significativa del mineral calcopirita. La muestra se pulverizó por molienda en el molino de bolas del laboratorio de procesos de la Facultad de Metalurgia. El mineral molido se tamizó, usando la malla Tyler 100 y se separó en cantidades de $77 \mathrm{~g}$.

\section{Inicio de la experimentación}

Se instalaron 12 biorreactores aireados de capacidad 
Delgado, S. \& Castillo D. Efecto de la temperatura en el crecimiento microbiano y la biolixiviación sobre la calcopirita por un cultivo microbiano biolixiviante.

de 1 litro de PVC, considerando en la experimentación 4 tratamientos con 2 repeticiones y 1 control. Los 4 tratamientos experimentales fueron $25,40,55$ y $70^{\circ} \mathrm{C}$. En cada biorreactor se adicionó $700 \mathrm{ml}$ del medio $9 \mathrm{~K}$ Silverman y Lundgren modificado, $70 \mathrm{ml}$ del inoculo microbiano biolixiviante, $77 \mathrm{~g}$ del mineral calcopirita (10\% del volumen total) y aireación de 1vvm (Archilla, 2005).

El tratamiento control tuvo $70 \mathrm{ml}$ de medio $9 \mathrm{~K}$ en lugar de inóculo microbiano, conteniendo todos los demás otros componentes. La incubación se realizó a la temperatura de experimentación.

\section{Evaluación de la experimentación}

\section{a) Determinación de la concentración de biomasa} (recuento celular)

Se realizó conteo celular cada 24 horas del medio contenido en cada biorreactor con previa dilución de $10^{-1}$. El conteo se realizó con ayuda de una cámara de Neubauer y un microscopio de campo. Los conteos se graficaron expresados en unidades logarítmicas de cel/ml versus el tiempo, para establecer la curva de crecimiento microbiano y en ella el valor máximo de crecimiento; dado por el valor más alto de concentración microbiana.

\section{b) Evaluación del fierro total y fierro III por método de} espectrofotometría (Cabaña 2005)

Se realizó cada 48 horas desde el inicio de la fermentación en el laboratorio de Química general por un especialista.

\section{c) Determinación de la curva patrón para determinar Fe total y Fe III}

\section{Determinación de Fe total}

Se realizó una dilución de la muestra al 1/100. Se colocó $0,5 \mathrm{ml}$ de la muestra diluida en tubos de ensayo, se le adicionó $0,5 \mathrm{ml}$ de $\mathrm{H}_{2} \mathrm{SO}_{4} 3 \mathrm{M}, 1-2$ gota de $\mathrm{KMnO}_{4} 0,1 \mathrm{~N}$ y 3 $\mathrm{ml}$ de KSCN 2M; los tubos se enrazaron a $10 \mathrm{ml}$ con agua destilada y se realizó la lectura en el espectrofotómetro a 477 $\mathrm{nm}$. Los valores de absorbancia obtenidos se llevaron a la curva patrón para determinar la correspondiente concentración.

\section{Determinación de Fe III}

Se colocó 0,5 $\mathrm{ml}$ de la muestra diluida y se agregó 0,5 $\mathrm{ml}$ de $\mathrm{H}_{2} \mathrm{SO}_{4} 3 \mathrm{M}$ y $3 \mathrm{ml}$ de $\mathrm{KSCN} 2 \mathrm{M}$, luego se enrazó a 10 $\mathrm{ml}$ con agua destilada, se realizó la lectura en el espectrofotómetro a $477 \mathrm{~nm}$. El valor de absorbancia obtenido se llevó a la curva patrón para determinar la correspondiente concentración.

\section{Determinación de Fe II}

Se realizó por diferencia de Fe total con el Fe III: $\mathrm{Fe} I \mathrm{II}=\mathrm{Fe}$ total $-\mathrm{Fe}$ III

d) Evaluación de la biolixiviación de cobre total por absorción atómica

\section{Determinación del $\mathrm{Cu}$}

Se realizó cada 24 horas tomando del biorreactor
$10 \mathrm{ml}$ filtrándolo con filtro de membrana $\mathrm{N}^{\circ} 42$. El filtrado fue llevado al equipo de absorción atómica (Figura 2) de la Facultad de Ingeniería de la Universidad Nacional Jorge Basadre Grohmann, donde se determinó la lectura. Los valores de absorbancia obtenidos se llevaron a la curva patrón para determinar la correspondiente concentración de cobre. Los valores obtenidos ( $\mathrm{g} / \mathrm{l}$ ) se graficaron versus el tiempo para establecer la curva de biolixiviación y en ella el valor máximo de cobre biolixiviado dado por el valor más alto de concentración de cobre. Esta evaluación se aplicó solo en aquel tratamiento donde se presentó mayor biooxidación de Fe II.

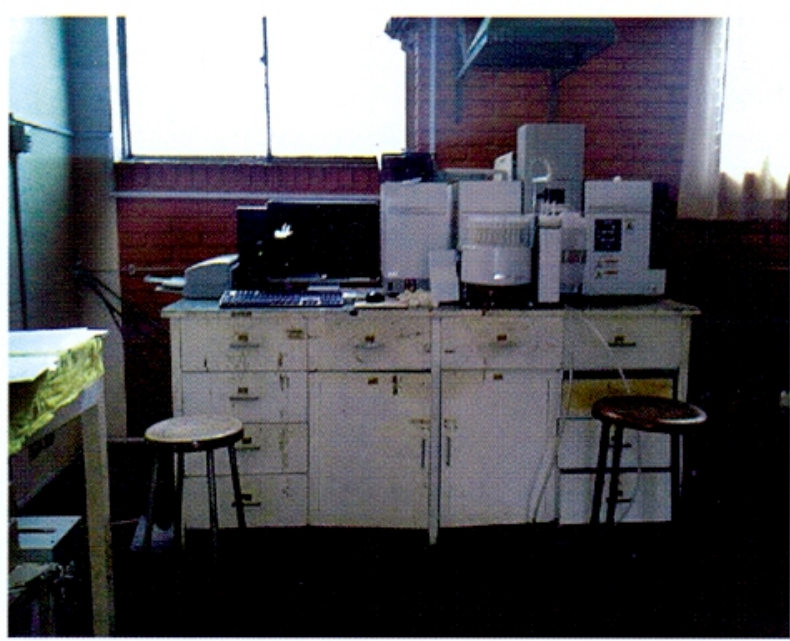

Figura 2. Equipo de Absorción Atómica

\section{e) Análisis Estadístico}

Se aplicó en el programa de Excel el ANOVA para establecer la diferencia significativa entre los tratamientos de concentración microbiana como el de los de biooxidación de Fe II.

Se determinó en el programa Excel la correlación entre el crecimiento microbiano, la biooxidación del Fe II y la biolixiviación del cobre.

\section{RESULTADOS}

\section{Determinación de concentración microbiana}

Se muestra que la mayor concentración microbiana se dio a $70^{\circ} \mathrm{C}$ y la menor a $25^{\circ} \mathrm{C}$ (Tabla 1$)$.

Se observa que la mayor concentración microbiana dada a la temperatura de $70^{\circ} \mathrm{C}$ se dio a las 312 horas de iniciado el proceso de biolixiviación del cobre (Figura 3).

Tabla 1. Valores de máximas concentraciones microbianas en unidades logarítmicas $\mathrm{cel} / \mathrm{ml}$, con sus repeticiones y promedio obtenidas a las temperaturas de $25,40,55$ y $70^{\circ} \mathrm{C}$ en el proceso de biolixiviación del cobre.

\begin{tabular}{cccc}
\hline Tratamientos & \multicolumn{3}{c}{ Mayor concentración microbiana } \\
& R1 & R2 & Promedio \\
\hline 25 & 8 & 8,08278537 & 8,041392685 \\
40 & 8,14824251 & 8,20394000 & 8,176091259 \\
55 & 8,10918125 & 8,18307482 & 8,146128036 \\
70 & 8,24139269 & 8,166847276 & 8,204119983 \\
\hline
\end{tabular}


Delgado, S. \& Castillo D. Efecto de la temperatura en el crecimiento microbiano y la biolixiviación sobre la calcopirita por un cultivo microbiano biolixiviante.

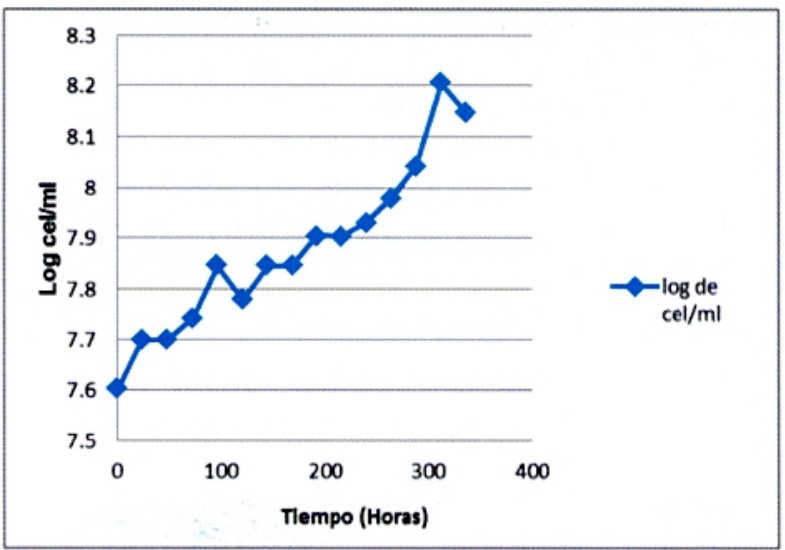

Figura 3. Curva de crecimiento microbiano a la temperatura de $70^{\circ} \mathrm{C}$ en la biolixiviación del cobre.

Por análisis de varianza, el Valor- P de 0,77 obtenido nos indica no hay una significancia estadística entre los valores de máximas concentraciones microbianas de los tratamientos con un $95 \%$ de nivel de confianza.

\section{Determinación del Fierro III}

Se muestra que la mayor concentración de Fe II biooxidado se dio a $70^{\circ} \mathrm{C}$ y la menor a $40^{\circ} \mathrm{C}$ (Tabla 2 ).

Tabla 2. Valores de máximas concentraciones de Fe II biooxidado en $\mathrm{g} / \mathrm{L}$, con repeticiones y promedio a las temperaturas de $25,40,55$ y $70^{\circ} \mathrm{C}$ en el proceso de biolixiviación del cobre.

\begin{tabular}{cccc}
\hline Tratamientos & \multicolumn{3}{c}{ Fierro II } \\
& R1 & R2 & Promedio \\
\hline 25 & 6,70022703 & 7,42078768 & 7,06050736 \\
40 & 5,52561445 & 6,66074425 & 6,09317935 \\
55 & 5,39729543 & 8,73358997 & 7,0654427 \\
70 & 10,0167802 & 12,9088935 & 11,4628369 \\
\hline
\end{tabular}

Se observa que la mayor formación de Fe III se dio a la temperatura de $70^{\circ} \mathrm{C}$, a las 144 horas después del inicio del proceso de biolixiviación del cobre (Figura 4).

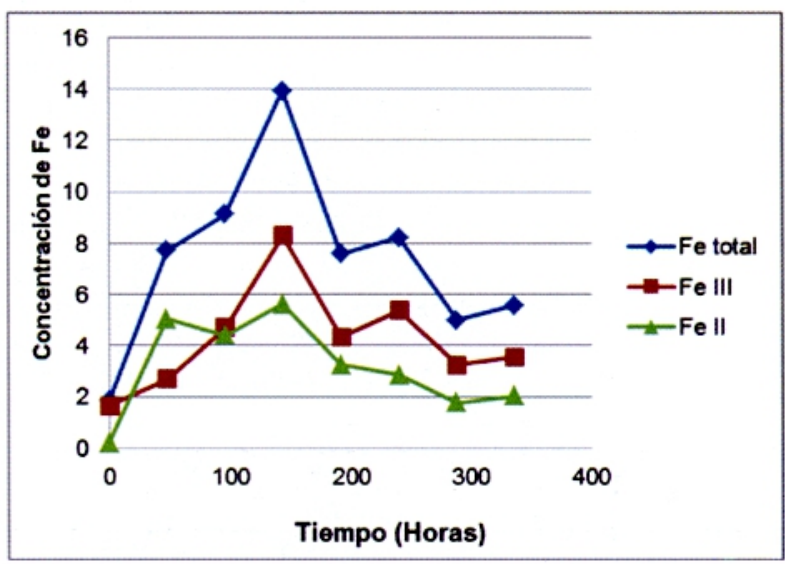

Figura 4. Curva de concentraciones del Fierro total, Fierro III y Fierro II obtenidos en el tratamiento experimental a la temperatura de $70^{\circ} \mathrm{C}$ del proceso de biolixiviación del cobre
Por análisis de varianza el valor- P de 0,11 obtenido nos indica no hay una significancia estadística entre los valores de máximas concentraciones de Fe II biooxidados de los tratamientos con un $95 \%$ de nivel de confianza.

\section{Determinación de la biolixiviación de cobre}

Se hizo en el tratamiento experimental donde se apreció una mayor biooxidación del Fierro II es decir en el tratamiento de $70^{\circ} \mathrm{C}$.

Se observa que la mayor concentración de cobre biolixiviado fue de 0,275038931 alcanzado a las 144 horas de iniciado el proceso a $70^{\circ} \mathrm{C}$ (Tabla 3) (Figura 5).

Tabla 3. Valores de concentración en $\mathrm{g} / \mathrm{l}$ de cobre obtenidos en el tratamiento experimental a la temperatura de $70^{\circ} \mathrm{C}$ en la biolixiviación sobre la calcopirita.

\begin{tabular}{cc}
\hline Horas & Concentración de Cu $(\mathrm{g} / \mathrm{l})$ \\
\hline 0 & 0,113303503 \\
48 & 0,206481244 \\
96 & 0,252587175 \\
144 & 0,275038931 \\
192 & 0,212335653 \\
240 & 0,235437898 \\
288 & 0,195580611 \\
336 & 0,221462222 \\
\hline
\end{tabular}

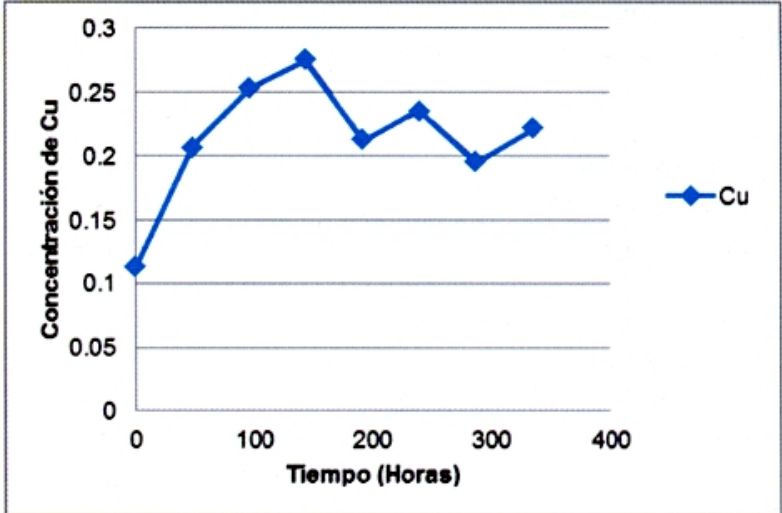

Figura 5. Curva de Concentración del Cobre obtenido en el tratamiento experimental de $70^{\circ} \mathrm{C}$ en la biolixiviación sobre la calcopirita.

\section{Determinación de correlación}

Se observa una correlación entre el crecimiento microbiano, la biooxidación del Fe II y la biolixiviación de cobre en el tratamiento a $70^{\circ} \mathrm{C}$ con un valor de alrededor de 0,9 (Tabla 4).

Tabla 4. Valores de correlación entre el crecimiento microbiano, biooxidación de Fe II y la biolixiviación de $\mathrm{Cu}$ a la temperatura de $70^{\circ} \mathrm{C}$ en el proceso de biolixiviación sobre la calcopirita.

\begin{tabular}{lc}
\hline \multicolumn{1}{c}{ Correlación } & Valores \\
\hline Concentración microbiana - Concentración de Fierro IIII & 0,922207698 \\
Concentración microbiana - Concentración de Cu & 0,964194326 \\
Concentración de Fierro III - Concentración de Cu & 0,882478032 \\
\hline
\end{tabular}


Delgado, S. \& Castillo D. Efecto de la temperatura en el crecimiento microbiano y la biolixiviación sobre la calcopirita por un cultivo microbiano biolixiviante.

\section{DISCUSIÓN}

La temperatura es uno de los principales factores físicos involucrados en el proceso de biolixiviación asimismo el factor biológico, el inóculo microbiano, usado en su fase logarítmica, después de cultivos sucesivos. La oxidación de Fe II por los microorganismos depende de las condiciones del medio ambiente, como también de la naturaleza cristaloquímica de los minerales portadores de la fuente de energía (Juárez, 2004).

El medio líquido 9K (Silverman \& Lundgren, 1959) modificado empleado para biolixiviantes, fue apropiado permitió el crecimiento y desarrollo adecuado del cultivo microbiano biolixiviante, hubo poca producción de jarosita en el biorreactor, esta impide el crecimiento de las bacterias y por tanto afecta la biolixiviación. La aireación de 1vvm utilizada fue la apropiada para la fermentación del desarrollo microbiano, estas bacterias necesitan un ambiente con oxígeno (1-1,5 vvm) para su crecimiento microbiano como para realizar la biolixiviación.

Una mayor concentración microbiana; $1,1 \times 10^{8}$ $\mathrm{cel} / \mathrm{ml}$; y de biooxidación; $12,90 \mathrm{~g} / 1$ dados en el tratamiento experimental de $70^{\circ} \mathrm{C}$, nos indica que la temperatura tuvo un efecto significativo en la cinética de disolución de la calcopirita. Es observable que al aumentar la temperatura se mejora la velocidad de disolución. A bajas temperaturas la acción de las bacterias disminuye y con ello la recuperación de cobre (Ibañez, 2012). La mayor tasa de solubilización de cobre ocurre a elevadas temperaturas $\left(>65^{\circ} \mathrm{C}\right)$, siendo así atractivo por ello el uso de microorganismos hipertermófilos hierro y azufre oxidantes en la biolixiviación.

Estudios indican, como regla general, la velocidad de las reacciones químicas se duplica con el aumento en $10^{\circ} \mathrm{C}$ en la temperatura. A pesar que la velocidad de descomposición es lo suficientemente rápida en $35-40^{\circ} \mathrm{C}$ para casi todos los minerales, para otros casos como calcopirita temperaturas en el intervalo $45-80^{\circ} \mathrm{C}$ son indispensables para hacer que el proceso sea económicamente viable (Rawling, 1994). En este trabajo al aumentar la temperatura hasta $70^{\circ} \mathrm{C}$ hubo un mejor crecimiento microbiano, mejor biooxidación y biolixiviación de cobre sobre la calcopirita.

En el proceso de biolixiviación realizado, se usaron consorcios microbianos. El cultivo microbiano biolixiviante nativo utilizado permitió un mejor proceso de biolixiviación del cobre a partir de la calcopirita. Este cultivo es un consorcio microbiano donde los microorganismos allí presentes interactúan entre sí, algunos de estos microorganismos necesitan del producto que genera un microorganismo precursor, creando así un ambiente propicio para el desarrollo de otro; se tiene descrito por ejemplo que se mejora la oxidación del mineral cuando las poblaciones son mixtas. Los co-cultivos de L.Ferroxidans y los oxidadores de azufre $T$. thiooxidans o T. caldos (termófilos moderados) han mostrado una más eficiente disolución de la calcopirita que en cultivos solos. El proceso de sinergismo, propicia sincronía metabólica a las bacterias termófilas moderadas Sulfobacillus spp y $A$. Ferooxidans que oxidan el azufre. (Ibañez, 2012) (Orrantia, 1997).

\section{CONCLUSIONES}

En las condiciones trabajadas se concluye lo siguiente:

La temperatura produce un efecto de incremento en el crecimiento del cultivo microbiano biolixiviante y en la biolixiviación del cobre a partir de la calcopirita directamente proporcional.

A la más alta temperatura de la experimentación, $70^{\circ} \mathrm{C}$, se obtuvo la más alta concentración microbiana biolixiviante, 8,204119983 unidades log. cel, y de cobre biolixiviado, $0,275038931 \mathrm{~g} / 1$.

\section{REFERENCIAS BIBLIOGRÁFICAS}

Acevedo, F. (2005). Fundamentos y Perspectivas de las tecnologias Biomineras. Valparaiso, Chile: Edición universitaria de Valparaíso, pag, 25-35.

Arias Sifuentes, E.; Piñeros Espinosa, P. (2008). Aislamiento e identificación de hongos filamentosos de muestras de suelo de los páramos de Guasca y Cruz Verde (Tesis de grado). Pontificia Universidad Javierana, 159.

Archilla, A. (2005). Uso de Biorreactores para la Lixiviación de un mineral oxidado, Universidad Nacional de Comahue, Argentina, pag. 23-30.

Cabaña, R. (2005). Determinación de sulfato ferroso por espectroscopia visible. Memoria. Encuentro de jóvenes investigadores, España.

CIMM, Centro de Investigación minera y metalúrgica. (2005). Biolixiviación la nueva minería. AntofagastaChile.

COCHILCO, Comisión chilena del cobre. (2009). Biolixiviación: Desarrollo Actual y sus Expectativas. Chile.

Constanza, L. (2000). Estudio piloto de aislamiento y fenotipificación de bacterias que participan en los procesos de biolixiviación, en las zonas mineras del Departamento de Boyaca (Tesis Doctoral). Universidad de Colombia. 187.

Ibáñez, T. y Velásquez, L. (2012). Lixiviación de la calcopirita en medios clorurados" Revista de Metalurgia de Chile.pp34-41.

Jeffrey y F. Lawson. (2000). Hydrometallurgy. 189-202.

Juárez, A. (2004). Biolixiviación de minerales sulfuroferroso en jales: aislamiento y caracterización de cultivos puros y mixtos de microorganismos involucrados (Tesis doctoral). Universidad de Colima.140.

Ly, M. (2003). Biolixiviación a nivel industrial, Encuentro Científico Internacional. Inf. IPEN. Perú.

Orrantia, E. (1997). Aislamiento y caracterización de cepas de Thiobacillus ferrooxidans con alta resistencia a arsénico y su utilización en la recuperación de oro a partir de concentrados de pirita y arsenopirita. (Tesis doctoral). Universidad Autónoma de Nuevo León. 256.

Rawlings, D., Kusano, T. (1994). Molecular genetics of Thiobacillus ferrooxidans. Microbiol. Rev. 58:39-55.

Rivadeneira, D. (2006). Adaptación de una cepa compatible con Acidithiobacillus ferrooxidans sobre concentrados de calcopirita $(\mathrm{CuFeS} 2)$, esfalerita $(\mathrm{ZnS})$ y galena 
Delgado, S. \& Castillo D. Efecto de la temperatura en el crecimiento microbiano y la biolixiviación sobre la calcopirita por un cultivo microbiano biolixiviante.

(PbS). Revista Colombiana de Biotecnologia, vol. XIII, nüm. 1, julio, 2011, pp. 132-143, Universidad Nacional de Colombia.

Rivera, R.E; Camejo, P.Y. (2011). Estudio de un mineral de sulfuros de cobre de baja ley con bacterias Tio y ferro oxidantes en condiciones témofilas. Revista de la facultad de Ingenieria. Universidad. Vol 26. Pp 6573. Universidad Autónoma de México.

Saavedra, A. (2009). "Solubilización del zinc a partir de! mineral esfalerita del Yacimiento minero "María Grimanesa” por lixiviación microbiana con cepas nativas" (Tesis de grado). Universidad Nacional Jorge Basadre Grohmann.182.

Segura, D. (1998). Aislamiento e identificación de bacterias ferrooxidantes y sulfooxidantes del área de Río tinto. (Tesis inédita de doctorado). Universidad de Sevilla, España.

Silverman, M. y Lundgren, D. (1959). Studies on the chemoautotrophic iron bacterium Ferrobacillus ferroxidans: an improved medium and harvesting procedure for securing high cell yields. Journal of Bacteriology. pp642-647.

\section{Correspondencia:}

Sandra Verónica Delgado Cruz: sandri_1091@hotmail.com
Fecha de Recepción: 15/09/2015

Fecha de Aceptación: 12/12/2015 